\title{
The Challenge of Human Psychology to Effective Management of the COVID-19 Pandemic
}

\author{
Petr Houdek ${ }^{1,2}$ • Petr Koblovský ${ }^{2,3,4} \cdot$ Marek Vranka $^{2}$ \\ Published online: 30 April 2021 \\ (C) The Author(s), under exclusive licence to Springer Science+Business Media, LLC, part of Springer Nature 2021
}

\begin{abstract}
When it comes to the nature of the COVID-19 pandemic and the effectiveness of measures against the disease, many citizens worldwide do not trust their governments or health authorities. This brief essay discusses several psychological mechanisms which, under certain conditions, lead people to ignore important sources of information and hinder effective management of the epidemic. The paper shows that understanding psychological mechanisms, such as information neglect, cognitive dissonance, psychological reactance, and, in general, the diversity of people's thinking styles, may help leaders design more effective government communications.
\end{abstract}

Keywords Backfire effect · Cognitive bias · COVID-19 · Government communication · Public health

\section{Introduction}

Why do people often not accept information that is both important for solving a social problem and useful for them personally? In the absence of vaccination, active communication by the public authorities could have been one of the most effective, yet cheapest, measures to avoid increasing the number of patients and deaths during the COVID-19 pandemic (Haug et al. 2020), that is, communication aimed at educating citizens about the need to use protective equipment and appropriate hygiene habits (such as social distancing). Communication by governments and health authorities was meant to reduce people's fears through evidence-based

Petr Houdek

petr.houdek@gmail.com

Petr Koblovský

petr.koblovsky@aya.yale.edu

Marek Vranka

vranka.marek@gmail.com

1 Faculty of Business Administration, Prague University of Economics and Business, Prague, Czechia

2 Faculty of Social Sciences, Charles University, Prague, Czechia

3 Center of Behavioral Experiments (CEBEX), Prague, Czechia

4 Institute for Behavioral and Economic Studies (INBES), Prague, Czechia discourse about the need to protect oneself and others. In general, proper health communication could significantly affect well-being, including disease prevention, health promotion, and quality of life (Van Bavel et al. 2020).

In countries worldwide, most citizens reacted strongly to the COVID-19 pandemic; they engaged in recommended social distancing and changed their hygiene behaviors according to the recommendations of health authorities; the public also believed that strong policy measures were necessary (Fetzer et al. 2020).

However, many citizens did not consider the official information and recommendations useful or trustworthy. Indeed, the perception of the health risk of COVID-19 as insignificant correlated to the actual non-adoption of preventative health behaviors (Dryhurst et al. 2020). Why were some individuals willing to endanger, possibly infect, and, in some cases, indirectly kill others by ignoring the recommendations and not using personal protective equipment?

\section{Information Ignorance May (Unfortunately) Be Important for Mental Health or Moral Self-Esteem}

One of the reasons why people avoid information is a possible threat to their moral feelings or self-esteem. They often do not look for information, do not want to know it rather than discover the truth, which may require action at some personal 
cost. Information neglect frees them from this responsibility. Consider an example of ignoring information about a humanitarian crisis.

In 2015 and 2016, asylum seekers flocked to Sweden, and the country faced a sudden need to accommodate these immigrants. Deployments to hostels and houses were arranged by the central office of the government, not local politicians, and the asylum seekers were scattered across Sweden in a quasirandom manner, regardless of the district's political, religious, or economic characteristics. Economist Eleonor Freddi was interested in how the Swedes' interest in the refugees' fate varied, depending on how their city was suddenly facing an induced migration crisis (Freddi 2020).

She found that the more asylum seekers were present in a given area, the less the Swedes became interested in media reports about them. In particular, if a newspaper article mentioned their own city or neighborhood by name, they ignored it. This finding is a paradox that contrasts with every lesson of the psychology of communication. After all, people are always attracted to information about their neighbors, the place where they live, and their surroundings. Freddi's analysis of the newspapers' headlines found that people from districts with many asylum seekers clicked fewer articles online about the poor living conditions of immigrants. The least read articles were about immigrant children and sick asylum seekers. From these results, it can be suggested that the potential for empathy was an inhibiting factor. That is, gaining information would create empathy which would produce a moral pressure to act; but if one were not willing to act, then one had to confront one's own coldness to the situation. Hence, many Swedes preferred to avoid the news - in order to avoid a decisionmaking dilemma. Research on judgment and decision making stresses the concept of the paradox of choice or the choice overload (Schwartz 2005): the more alternatives or options people know or gain, the less likely they are to opt for one because too many choices make decisions too complicated. Therefore, individuals begin to avoid information; then, they do not know their duties or the consequences of their inaction.

\section{Drowning in Information: Motivational and Confirmation Biases}

The processing of information consumes time and attention, which are necessarily limited (Houdek et al. 2018). Simultaneously, every crisis and catastrophe explodes with data, news, and opinions - which sometimes prove to be, in retrospect, erroneous, or at least incomplete. In emergencies, few people can distinguish truthfulness and completeness of news from partial sources, so they may evaluate all media sources based on the worst of them. It may even be suggested that this leads the media to produce more and more news, which can be less and less informative on average (Akerlof
1978). Ideally, people must filter the news intensively (Hills 2019). Yet, one method in the face of a flood of information is limiting oneself to existing beliefs, or the attitudes of one's social bubble.

The problem with this filter is that it leads to errors and polarization. Of course, no one can process all the information correctly. But when people digest only information that confirms their existing views, the errors multiply. One moves further and further away from reality, and the possibility of changing one's opinion and behavior becomes remote. To admit a mistake would be to doubt oneself. What often emerges instead is the demonization of the authorities' or others' views. As British comedian John Cleese said: "The great thing about having enemies is that you can pretend that all the badness in the whole world is in your enemies and all the goodness in the whole world is in you" (Kottke 2020). Combating misinformation, fake news, and conspiracy theories remains a challenge because people tend to consume information within like-minded echo chambers or selectively ignore information inconsistent with their beliefs.

Consider the extreme example of the Holocaust. One might predict that the Germans living today around the former concentration camps are more tolerant and cosmopolitan. However, some evidence suggests that they are not. It is psychologically difficult to accept that someone in the family or a neighbor may have been involved, even indirectly, in the horrors of Nazism. A more comfortable attitude is the belief that some groups of people may not really be equal and that "something" about Nazism must have been right (Homola et al. 2020). Studies from the USA show the same results. American families living on or near former slave plantations are more likely to oppose affirmative action and express racial resentment and colder feelings toward blacks (Acharya et al. 2016).

\section{Backfire Effects of Threats and Sanctions}

People are not necessarily more likely to follow rules when they are threatened by punishment for breaking the rules. They often show the so-called psychological reactance (Miron and Brehm 2006), i.e., the need for freedom which is activated whenever individuals feel a restriction on their options or behavior, leading them to desire to regain their freedom by engaging in the restricted behavior. Everyone has a different sense of personal autonomy and freedom from external authorities. When threatened, albeit trivially, some people's strong aversion to being coerced leads them to defiance and contempt. Disobedience becomes a way to show one's autonomy. There is also evidence that people carry out socalled antisocial punishment (Herrmann et al. 2008; Kuběna et al. 2014); i.e., they actively harm individuals who adhere to these social norms or try to maintain such norms. 
Such dynamics may be illustrated by the following experiment conducted by Cagala et al. (2019). The participants in their study could earn a bonus $€ 5$ based on their report of a number randomly drawn from the set ranging from 0 to 6 . When they reported number 5 , they received the bonus, but for any other reported number, they received nothing. The participants, however, could easily lie about the outcome of the draw and earn the bonus even though the number 5 had not been drawn. Around $28 \%$ of participants lied in the control condition and the proportion of cheaters fell to $12 \%$ when participants were asked to sign the following commitment at the start of the experimental session: "I hereby declare that I will behave honestly." However, when the signed commitment contained explicit sanction ("I hereby declare that I will not break the rules described in the instructions. Violation of the rules may lead to exclusion from all future experiments.") and thus was more reactance provoking, the rate of cheating rose to almost $47 \%$. Among participants with the highest reactance trait, cheating in the group with the reactance provoking commitment was close to $100 \%$. Thus, threats and sanctions may lead at least some citizens to actively oppose even well-meant and reasonable rules.

If people cannot be persuaded by governmental communication to follow the rules willingly, nothing is left to enforce the rules but draconian measures and harsh punishments. However, such an approach may work only in the short term. In the long run, it may provoke punishment avoidance, growing psychological reactance and strengthen polarization in society, further breaking down trust in public authorities. It is essential for the authorities to first (re)gain citizens' trust or, alternatively, rely on institutions that people still trust for enforcement of the protective measures.

\section{Conclusion}

In many countries worldwide, citizens have frequently exhibited mistrust of their governments or health authorities as concerns the nature of the COVID-19 pandemic and the importance of taking precautions against the disease. This article suggests that several psychological mechanisms can, under certain conditions, lead to the ignoring of important sources of information and can hinder effective social actions.

Behavioral scientists have come up with communication proposals that factor in these psychological mechanisms (e.g., Van Bavel et al. 2020). The idea is to inform government and health organizations about the diversity of people's thinking, so as to avoid unexpected negative backslashes. Several communication strategies informed by psychological research seem to be useful, including emphasizing the direct benefits to recipients of the information; focusing on protecting important others (like parents, children, or vulnerable individuals); aligning with the recipient's moral and/or political values; or appealing to social norms as well as the scientific consensus (Van Bavel et al. 2020).

On the other hand, the behavioral sciences may not be mature enough to provide really effective measures. Many recommendations are based on correlational studies or laboratory experiments examining hypothetical scenarios and were often obtained from student samples. Generalization of the results obtained in this way is difficult, especially when considering complex and life-and-death situations like pandemics (IJzerman et al. 2020). The COVID-19 crisis demonstrates a critical need for further efforts to bring the humanities as well as the social and behavioral sciences to bear on actual crises and policies in order to produce a more effective body of problem-solving research.

\section{Further Readings}

Acharya, A., Blackwell, M., \& Sen, M. 2016. The Political Legacy of American Slavery. The Journal of Politics, 78(3), 621-641. doi: https://doi.org/10.1086/686631

Akerlof, G. A. 1978. The Market for "Lemons": Quality Uncertainty and the Market Mechanism. In P. Diamond \& M. Rothschild (Eds.), Uncertainty in Economics (pp. 235-251). New York: Academic Press.

Cagala, T., Glogowsky, U., \& Rincke, J. 2019. Content Matters: The Effects of Commitment Requests on Truth-Telling. Available at SSRN 3432445. doi: https://doi.org/10.2139/ssrn.3432445

Dryhurst, S., Schneider, C. R., Kerr, J., Freeman, A. L. J., Recchia, G., van der Bles, A. M., ..., van der Linden, S. 2020. Risk Perceptions of COVID-19 Around the World. Journal of Risk Research, 23(7-8), 994-1006. doi: https://doi.org/10.1080/13669877.2020.1758193

Fetzer, T. R., Witte, M., Hensel, L., Jachimowicz, J., Haushofer, J., Ivchenko, A., . . . Fiorin, S. 2020. Global Behaviors and Perceptions at the Onset of the COVID-19 Pandemic. National Bureau of Economic Research, 27082. doi: https://doi.org/10. 3386/w27082

Freddi, E. 2020. Do People Avoid Morally Relevant Information? Evidence from the Refugee Crisis. The Review of Economics and Statistics, 1-45. doi: https://doi.org/10.1162/rest a 00934

Haug, N., Geyrhofer, L., Londei, A., Dervic, E., Desvars-Larrive, A., Loreto, V., ..., Klimek, P. 2020. Ranking the Effectiveness of Worldwide COVID-19 Government Interventions. Nature Human Behaviour, 4(12), 1303-1312. doi: https://doi.org/10.1038/s41562020-01009-0

Herrmann, B., Thöni, C., \& Gächter, S. 2008. Antisocial punishment across societies. Science, 319(5868), 1362-1367. doi: https://doi. org/10.1126/science. 1153808

Hills, T. T. (2019). The Dark Side of Information Proliferation. Perspectives on Psychological Science, 14(3), 323-330. doi: https://doi.org/10.1177/1745691618803647

Homola, J., Pereira, M. M., \& Tavits, M. 2020. Legacies of the Third Reich: Concentration Camps and Out-group Intolerance. American Political Science Review, 114(2), 573-590. doi: https://doi.org/10. 1017/s0003055419000832

Houdek, P., Koblovský, P., Št’astný, D., \& Vranka, M. 2018. Consumer Decision Making in the Information Age. Society, 55(5), 422-429. doi: https://doi.org/10.1007/s12115-018-0283-5 
IJzerman, H., Lewis, N. A., Przybylski, A. K., Weinstein, N., DeBruine, L., Ritchie, S. J., . . Anvari, F. 2020. Use Caution When Applying Behavioural Science to Policy. Nature Human Behaviour. doi: https://doi.org/10.1038/s41562-020-00990-w

Kottke, J. 2020. John Cleese on Extremism. Retrieved from https:// kottke.org/20/06/john-cleese-on-extremism

Kuběna, A. A., Houdek, P., Lindová, J., Př́íplatová, L., \& Flegr, J. 2014. Justine Effect: Punishment of the Unduly Self-Sacrificing Cooperative Individuals. PLoS ONE, 9(3), e92336. doi: https://doi. org/10.1371/journal.pone.0092336

Miron, A. M., \& Brehm, J. W. 2006. Reactance Theory - 40 Years Later. Zeitschrift für Sozialpsychologie, 37(1), 9-18. https://doi.org/10. 1024/0044-3514.37.1.9

Schwartz, B. 2005. The Paradox of Choice: Why More is Less. New York: Harper Perennial.

Van Bavel, J. J., Baicker, K., Boggio, P. S., Capraro, V., Cichocka, A., Cikara, M., ..., Willer, R. 2020. Using Social and Behavioural Science to Support COVID-19 Pandemic Response. Nature Human Behaviour, 4(5), 460-471. doi: https://doi.org/10.1038/ s41562-020-0884-z

Publisher's Note Springer Nature remains neutral with regard to jurisdictional claims in published maps and institutional affiliations.
Petr Houdek is an associate professor and the director of the Research and Science Center at the Faculty of Business Administration of Prague University of Economics and Business. He is also an associate professor at the Faculty of Social Sciences of Charles University in Prague. His primary research interests include behavioral economics, social psychology, and management sciences.

Petr Koblovský is an assistant professor at the Faculty of Social Sciences of Charles University in Prague. His main research interests include economic and moral decision-making and behavioral law and economics. $\mathrm{He}$ is the chairman of the board of directors of the Center of Behavioral Experiments (CEBEX) and of the Institute for Behavioral and Economic Studies (INBES).

Marek Vranka is a research psychologist at the Faculty of Social Sciences of Charles University and the Faculty of Business Administration of Prague University of Economics and Business. He leads the Prague Laboratory for Experimental Social Sciences, and his main research interests are focused on moral judgment, decision-making, and dishonesty. Also, he lectures on behavioral economics, methodology, and statistical analysis. 